Dokuz Eylül Üniversitesi-Mühendislik Fakültesi

Fen ve Mühendislik Dergisi

Cilt 20, Sayı 58, Ocak, 2018
Dokuz Eylul University-Faculty of Engineering Journal of Science and Engineering Volume 20, Issue 58, January, 2018

DOI: $10.21205 /$ deufmd. 2018205801

\title{
Gözenekli ZrB2 Peletlerin Farklı Sıcaklıklardaki Oksidasyon Davranışları
}

\section{Esra DOKUMACI ${ }^{*}$, İlker ÖZKAN² ${ }^{2}$ A.Bülent ÖNAY ${ }^{3}$}

${ }^{1}$ Dokuz Eylül Üniversitesi, Mühendislik Fakültesi, Metalurji ve Malzeme Mühendisliği Bölümü, 35390, İzmir (ORCID: 0000-0003-3886-3963)

2Dokuz Eylül Üniversitesi, Torbalı Meslek Yüksekokulu, Endüstriyel Cam ve Seramik Programı, 35860, İzmir (ORCID: 0000-0002-7506-5795)

${ }^{3}$ Dokuz Eylül Üniversitesi, Mühendislik Fakültesi, Metalurji ve Malzeme Mühendisliği Bölümü, 35390, İzmir (ORCID: 0000-0002-2830-1898)

(Alınış / Received: 27.10.2016, Kabul / Accepted: 08.11.2017, Online Yayınlanma / Published Online: 20.01.2018)

Anahtar Kelimeler Özet: Bu çalışmada soğuk preslenmiş gözenekli $\mathrm{ZrB}_{2}$ peletlerinin Döngüsel oksidasyon, zirkonyum diborür $\left(\mathrm{ZrB}_{2}\right)$, oksidasyon davranışı. farklı sıcaklıklardaki döngüsel oksidasyon davranışları incelenmiştir. Oksidasyon deneyleri $800^{\circ} \mathrm{C}, 1000^{\circ} \mathrm{C}$ ve $1200^{\circ} \mathrm{C}$ sıcaklıklarda $1,2,5,10,15$ ve 20 saat süreler ile yapılmıştır. Deneylerin sonucunda korozyon ürünü olarak $\mathrm{ZrO}_{2}, \mathrm{ZrB}_{2}, \mathrm{~B}_{7} 0$ ve $\mathrm{B}_{2} \mathrm{O}_{3}$ fazlarının oluştuğu tespit edilmiştir. Aynı zamanda peletlerin oksidasyon davranışlarının sıcaklığa ve zamana bağlı olduğu gözlenmiştir. Analiz sonuçları ve mikroyapılar değerlendirildiğinde, oluşan $\mathrm{B}_{2} \mathrm{O}_{3}$ fazının farklı sıcaklıklardaki davranışının numunelerin oksidasyon davranışında önemli bir etkisi olduğu sonucuna varılmıştır.

\section{Oxidation Behavior of Porous $\mathrm{ZrB}_{2}$ Pellets at Different Temperatures}

\section{Keywords}

Cyclic oxidation, zirconium

diboride $\left(\mathrm{ZrB}_{2}\right)$, oxidation

behaviour
Abstract: In this study, cyclic oxidation of cold pressed porous $\mathrm{ZrB}_{2}$ pellets at different temperatures was investigated. Oxidation tests were performed at $800^{\circ} \mathrm{C}, 1000^{\circ} \mathrm{C}$, and $1200^{\circ} \mathrm{C}$ for $1,2,5,10$, 15 and 20 hours. As a result of experiments, $\mathrm{ZrO}_{2} \mathrm{ZrB}_{2}, \mathrm{~B}_{7} 0$ and $\mathrm{B}_{2} \mathrm{O}_{3}$ have been found to occur as corrosion product. At the same time it was observed that oxidation behaviour of pellets depend on temperature and time. When analysis results and microstructures were evaluated, it is concluded that behavior of the $\mathrm{B}_{2} \mathrm{O}_{3}$ phases at different temperatures has a significant effect on the oxidation of the samples. 


\section{Giriş}

Zirkonyum diborür $\left(\mathrm{ZrB}_{2}\right)$, hafnium diborür ile birlikte "çok yüksek sıcaklık seramikleri" (Ultra High Temperature Ceramics) olarak tanımlanmıştır. Bu tür malzemelerin önemi, hipersonik hızlarda atmosferde uçabilecek ve uzay yolculuklarında birçok kez kullanılabilecek araçların geliştirilmesi üzerine yapılan çalışmalar nedeniyle artmıştır. $\mathrm{Bu}$ araçların güvenli çalışmaları için atmosfer katmanlarıyla olan sürtünmelerde ortaya çıkan $1500^{\circ} \mathrm{C}$ ve üzerindeki sıcaklıklarda atmosfer ortaminda oksijenden etkilenmeyecek malzemeler gerekmektedir [1-7].

Zirkonyum diborür, düşük yoğunluk $\left(6.085 \mathrm{~g} / \mathrm{cm}^{3}\right)$, yüksek ergime sicaklığı $\left(3245^{\circ} \mathrm{C}\right)$, yüksek elektriksel ve termal iletkenliği (60-130 W/mK), ergimiș metallere ve bazik olmayan cüruflara karşı olan inert kimyasal davranışları ve üstün termal şok direnci olan bir malzemedir [2]. Bu özellikleriyle $\mathrm{ZrB}_{2}$, yüksek sıcaklık ve korozyon direncinin gerektiği uygulamalarda kullanılabilir. Fakat yüksek yoğunluklu $\mathrm{ZrB}_{2}$ üretmek oldukça zordur. Son zamanlarda yapılan çalışmalar, $\mathrm{SiC}, \mathrm{MoSi}_{2}$ veya $\mathrm{TaSiO}_{2}$ gibi Si-içerikli bileşikler ilave edilerek $\mathrm{ZrB}_{2}$ 'nin yoğunluğunu artırmak üzerine yoğunlaşmaktadır [2, 8-11].

Yüksek sıcaklıklardaki üstün özelliklerinden dolayı $\mathrm{ZrB}_{2}$ 'ün yüksek sıcaklıklardaki oksidasyon davranışları büyük öneme sahiptir. Katkısız $\mathrm{ZrB}_{2}$ malzemenin oksidasyon davranışları üzerine çalışmalar bulunsa da çalışmaların büyük bir çoğunluğu yukarıda bahsedilen katkı malzemeleri ile yoğunluğu artırılmış $\mathrm{ZrB}_{2}$ esaslı seramik malzemeler kullanılarak yapılmaktadır. Ayrıca literatürde geçiş metallerinin ilave edildiği $\mathrm{ZrB}_{2}$ seramiklerinin oksidasyon dirençleri hakkında da çalışmalar mevcuttur [1214].
Literatür araștırmalarının sonucunda soğuk preslenmiş gözenekli $\mathrm{ZrB}_{2}$ seramiklerin oksidasyon davranışları hakkında yapılan bir çalışma bulunmadığı görülmüștür. $\quad \mathrm{Bu}$ çalışmanın amacı soğuk preslenmiș $\mathrm{ZrB}_{2}$ seramiklerin oksidasyon davranışlarını incelemektir.

\section{Materyal ve Metot}

Bu çalışmada kullanılan $\mathrm{ZrB}_{2}$ tozları Alfa Aesar firmasından temin edilmiştir. Üretici firmadan alınan bilgilere göre $\mathrm{ZrB}_{2}$ toz taneleri yaklaşık -325 mesh $(<44 \mu \mathrm{m})$ boyutundadır. Pelet hazırlığ sırasında tozların plastikliğini geliştirmek ve mekanik dayanımını artırmak amacıyla, ağırlıkça \%4 karboksimetil selüloz (CMC) katkılı su çözeltisi kullanılmıştır. Tozlar çapı 20 mm olan kalıba yerleștirilerek soğuk presleme metodu ile pelet haline getirilmiş ve $110^{\circ} \mathrm{C}$ sicaklıkta kurutulmuştur.

Oksidasyon deneyleri sonrası ağırlık değişimlerini daha doğru ölçmek amaciyla, peletler geniş yüzeylerine açılan deliklerden geçirilen tel yardımıyla kuvars potalara asılarak deneye tabi tutulmuşlardır. Oksidasyon deneyleri durgun hava ortamında $800^{\circ} \mathrm{C}$, $1000^{\circ} \mathrm{C}$ ve $1200^{\circ} \mathrm{C}$ sicaklıklarda $1,2,5$, 10,15 ve 20 saat süreyle yapılmıştır. Deney öncesi ve sonrası peletlerin ağırlıkları ve boyutları ölçülerek ağırlık değişimi-zaman grafikleri hazırlanmıştır. Ayrıca ZrB2 toz hammaddesinin sıcaklık artışı ile bünyesinde meydana gelen termal ve gravimetrik değişimleri belirlemek amaciyla Shimadzu DTG-60H model DTA-TG cihazı kullanılmıştır. $\begin{array}{lcr}\text { Deneylerde } & \text { kullanilan toz } \\ \text { hammaddelerin } & \text { ve oksidasyon }\end{array}$ deneyleri sonrası peletlerin mikroyapı incelemeleri JEOL JSM-6060 model 
Taramalı Elektron Mikroskobunda (SEM) ikincil elektron görüntüleri (SEI) kullanılarak yapılmıştır. Oksidasyon deneyleri sonrası yüzeyde oluşan tabakaların element analizleri Enerji Dağılım Spektrometresi (EDS) ile yapılmıştır. Oluşan korozyon ürünlerinin kristal yapıdaki fazlarını belirlemek amacıyla Rigaku D/Max2200/PC model X-ışınları difraktometresi (XRD) kullanılmıştır.

\section{Bulgular}

\section{1. $\mathrm{ZrB}_{2}$ Tozunun Karakterizasyonu}

İşlem görmemiş $\mathrm{ZrB}_{2}$ toz hammaddesinin SEM görüntüsü Şekil $1 a^{\prime} d a$ verilmektedir. Bu görüntüye göre $\mathrm{ZrB}_{2}$ tozu köşeli ve bazı kısımlarda topaklanmış halde bulunmaktadır.

$\mathrm{ZrB}_{2}$ tozu üzerinde yapılan XRD analizi sonucu Şekil 1b'de gösterilmektedir. XRD analizinde toz malzeme içerisinde yalnızca Zirkonyum diborür fazı (0340423 katalog numaralı) saptanmıştır.
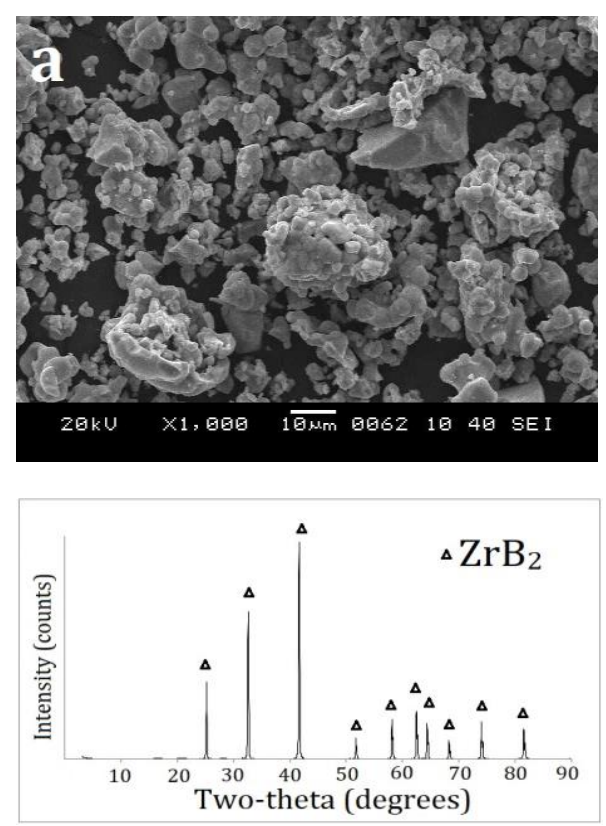

Şekil 1. İșlem görmemiș $\mathrm{ZrB}_{2}$ toz hammaddesinin (a) SEM görüntüsü ve (b) XRD analizi
$\mathrm{ZrB}_{2}$ tozunun DTA analizinde $400^{\circ} \mathrm{C}$ civarında bașlayan küçük ekzotermik pikler görülmüştür. Fakat gözlenebilir ağırlı artışı $650^{\circ} \mathrm{C}$ dolaylarında başlamıştır. Ağırlığın artmaya devam ettiği sıcaklıklarda DTA verilerinde de küçük de olsa pikler görülmeye devam etmiștir. DTA verileri, $950^{\circ} \mathrm{C}$ civarında malzeme yapısında değişiklikler olduğuna işaret etmektedir.

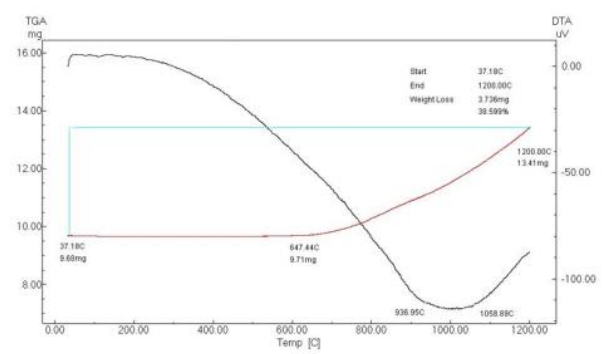

Şekil 2. Toz $\mathrm{ZrB}_{2}$ hammaddesinin DTA-TG analiz sonucu

\subsection{Oksidasyon Çalışmaları}

Sekil 3'te numunelerin 1000 ve $1200^{\circ} \mathrm{C}$ oksidasyon deneyi sonrası kesit mikroyapıları görülmektedir. $1000^{\circ} \mathrm{C}^{\prime} \mathrm{de}$ 2 saat oksidasyon sonrası $\mathrm{ZrB}_{2}$ peletindeki taneler bir araya gelerek kümeler oluşturmuștur. Kümeler arasında da büyük gözenekler bulunmaktadır. $1200^{\circ} \mathrm{C}^{\prime} \mathrm{de} \quad 15$ saat oksidasyon sonrası incelenen SEM görüntülerinde ise yüzeydeki oksitlenmiş $\mathrm{ZrB}_{2} \quad$ tanelerinin birbirleriyle birleştikleri gözlenmiştir (Şekil 3c-3d). Deney şartlarının pelet numunenin sinterlenmesi için yeterli olmadığı düșünülürse, tanelerin birbirlerine tutunmasını sağlayan yapının, deney sıcaklığında ergimiş halde bulunacak amorf bor oksit fazı olduğu öne sürülebilir. 

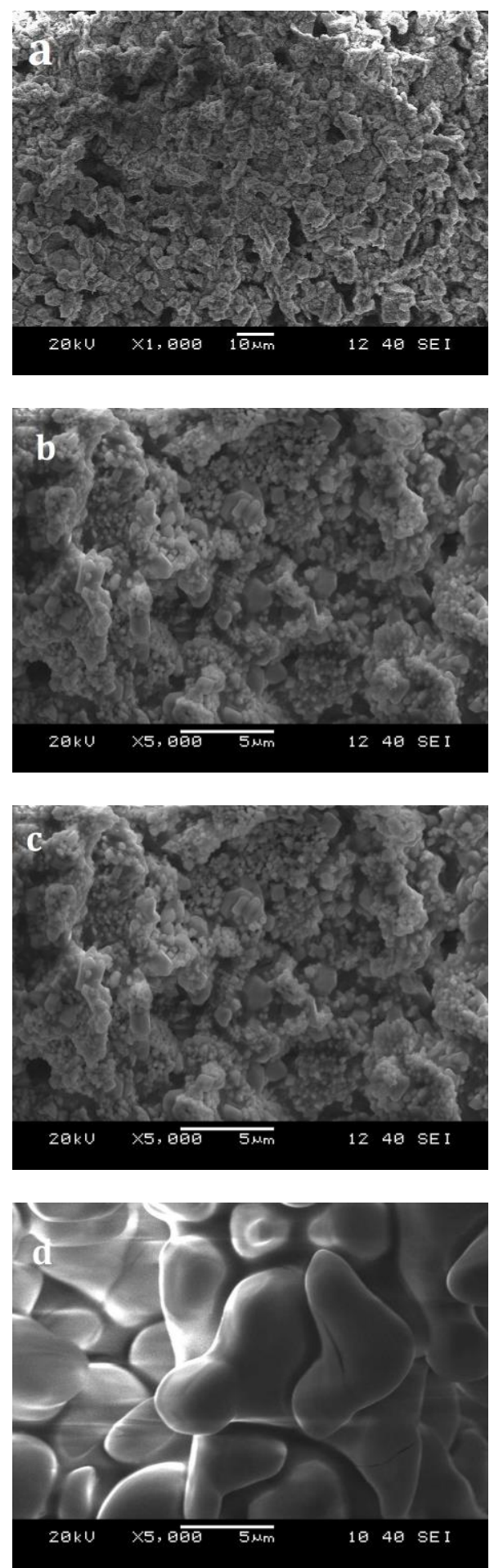

Şekil 3. (a-b) $1000^{\circ} \mathrm{C}^{\prime}$ de 2 saat ve (c-d) $1200^{\circ} \mathrm{C}^{\prime}$ de 15 saat oksitlenen $\mathrm{ZrB}_{2}$ pelet kesitlerinin SEM görüntüleri
Şekil 4, $1000^{\circ} \mathrm{C}^{\prime} \mathrm{de}$ oksitlenen pelet numunenin XRD analiz sonucunu göstermektedir. Buna göre numunede $\mathrm{ZrO}_{2}, \quad \mathrm{ZrB}_{2}, \mathrm{~B}_{7} 0$ fazlarının oluştuğu saptanmıştır. $\mathrm{B}_{2} \mathrm{O}_{3}$ fazına karşılık gelen birkaç pik bulunmuşsa da, bu fazın kristal halinde mi yoksa amorf olarak mı bulunduğu tespit edilememiștir.

ZrB2 peletler kullanılarak farklı sıcaklık ve sürelerde yapılan oksidasyon deneylerinin sonuçları Şekil 5'te bir arada verilmektedir. Tüm sıcaklıklar için, 5 saat süre ile yapılan deneylerde hızlı bir ağırlık kazanımı olurken 10, 15, 20 saat süreli deneylerde daha yavaş artan ağırlık kazanımı gözlemlenmiștir. Deney sicaklığının artmasıyla numunelerin oksitlenme miktarının arttığı açıkça görülmesine rağmen, 800 ile $1000^{\circ} \mathrm{C}$ 'de yapılan 15 ve 20 saatlik deneylerde benzer ağırlık artışları olması dikkat çekicidir.

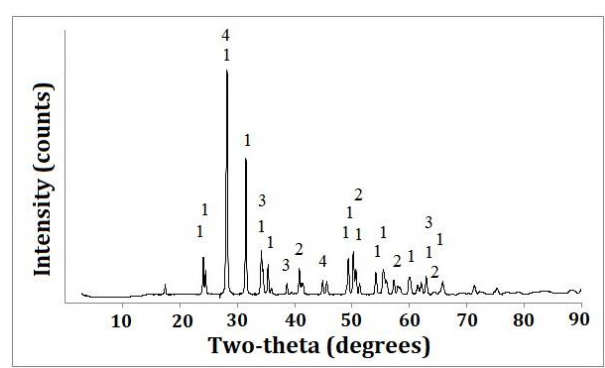

Şekil 4. $1000^{\circ} \mathrm{C}$ 'de 2 saat oksitlenen $\mathrm{ZrB}_{2}$ peletin XRD grafiği $\left(1-\mathrm{ZrO}_{2}, 2-\mathrm{ZrB}_{2}, 3-\mathrm{B}_{7} \mathrm{O}\right.$, 4$\mathrm{B}_{2} \mathrm{O}_{3}$ )

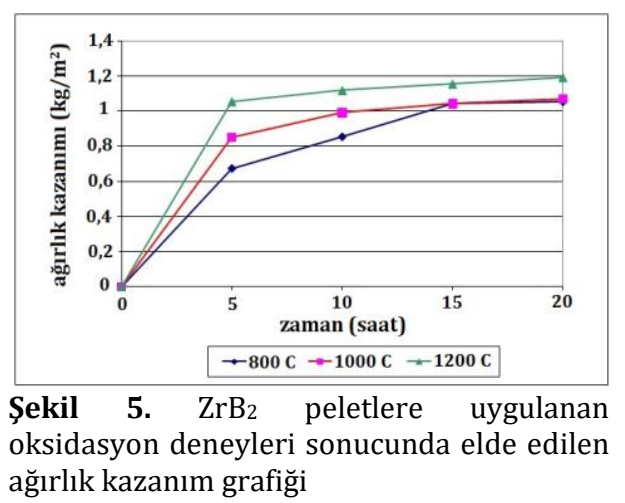


İncelenen $\mathrm{ZrB}_{2}$ bileşiğinin ve bu bileşiğin oksijen içeren ortamlarla yaptıkları kimyasal tepkimeler sonucunda ortaya çıkan ürünlerin termodinamik kararlılıkları oksitlenme tepkimelerinin Standart Gibbs Serbest Enerji Değişimlerinin $\left(\Delta \mathrm{G}^{\circ}\right)$ sayısal değerleri göz önüne alınarak belirlenebilir. Tablo 1'de, bu bileșiğin değişik sıcaklıklardaki durumları da düşünülerek, yazılabilecek oksitlenme tepkimesi ile bu tepkimenin literatürdeki kaynaklardan derlenen veriler kullanılarak hesaplanan $\left(\Delta G^{\circ}\right)$ değerleri gösterilmiştir.

Tablo 1'de verilen $\Delta \mathrm{G}^{\circ}$ değerlerinden oksitlenme tepkimelerinin yazıldığ şekilde gerçekleşebileceği ve belirtilen deney sicaklıklarında $B$ ve $\mathrm{Zr}$ elementlerinin oksitlerinin korozyon ürünleri olarak ortaya çımalarının termodinamik açıdan mümkün olduğu görülmektedir.

$\mathrm{ZrB}_{2}$ numuneleri için verilen XRD sonucu, hava ortamında oksitlenen bu bileşiğin, beklenildiği gibi, katı $\mathrm{ZrO}_{2}$ fazını oluşturduklarını göstermiştir. Bor içeren bileşiklerin ortak korozyon ürünü olan Bor oksit $\left(\mathrm{B}_{2} \mathrm{O}_{3}\right)$ fazının, ergime sıcaklığının $450^{\circ} \mathrm{C}$ civarında olması nedeniyle bu faz, $450^{\circ} \mathrm{C}$ 'den daha yüksek sıcaklıklarda sıvı olarak bulunacaktır. Literatürde, bu fazın kaynama noktasının $1600^{\circ} \mathrm{C}$ civarında olduğu, $1000^{\circ} \mathrm{C}^{\prime}$ den yüksek sıcaklıklarda sıvı bor oksidin buhar basıncının önemli ölçüde arttığı belirtilmiştir [4, 16]. Fakat başka çalışmalarda da bor oksit buhar basincının korozyona etkisinin $750^{\circ} \mathrm{C}^{\prime}$ den itibaren görüldüğü belirtilmiştir [17].

$\mathrm{Bu}$ çalışmada da $1000^{\circ} \mathrm{C}^{\prime}$ de ve hava ortamında oksitlenen $\mathrm{ZrB}_{2}$ numunesinin XRD analizinde, deney sıcaklığında sıvı halde bulunan fakat numunenin soğuması sırasında amorf yapıda katılaşan $\mathrm{B}_{2} \mathrm{O}_{3}$ bileşiği görülmüştür.

Bor bileşiklerinin oksitlenme davranışlarının kinetik açıdan değerlendirilmesi de korozyon ürünlerinin yukarıda belirtilen fiziksel özelliklerinin yanı sıra pelet numuneler için ölçülen ağırlık değişimlerinin incelenmesiyle yapılabilir. Çünkü ölçülen ağırlık değişimlerinin deney süresi ve sıcaklığına bağlı olarak değişmesinde korozyon ürünlerinin özelliklerinin önemli etkileri vardır. Örneğin, oksitlenme sonucunda yalnızca katı haldeki ürünlerin bulunduğu ve bu ürünlerin deney sirasinda veya sonrasında numune yüzeyinden ayrılmadan (dökülmeden) kaldığı durumlarda, oksitlenen numunenin ağırlığında net artış olması beklenir. Fakat, yalnızca gaz halindeki korozyon ürünlerinin oluștuğu numunelerde ise net ağırlık kayıpları olacaktır. Oksitlenme sırasında yalnızca sıvı fazların oluşması ise, bu fazların buhar basınçları, deney süresi ve sıcaklığıyla orantılı olarak numunelerde ağırlık artışları veya kayıplarına neden olabilir.

$\mathrm{Bu}$ çalışmada da gözlendiği gibi incelenen $\quad \mathrm{ZrB}_{2} \quad$ bileşiğinin oksitlenmeleri sonucunda farklı hallerdeki korozyon ürünleri aynı anda ortaya çıkmaktadır. $\mathrm{Bu}$ durumda, numunelerin birim yüzey alanına düşen (özgül) ağırlık değişimlerinin [( $\Delta \mathrm{m} / \mathrm{A})]$, korozyon ürünlerinin özellikleri ile deney şartlarına (deney süresi $(\mathrm{t})$ ve sıcaklığı (T)) bağlı olarak değişmeleri beklenir.

Çalışılan tüm sıcaklıklarda, $\quad \mathrm{ZrB}_{2}$

Tablo 1. Oksitlenme tepkimesi ve Standart Gibbs Serbest Enerji Değișimleri $\left(\Delta \mathrm{G}^{\circ}\right)$ [15].

\begin{tabular}{|c|c|c|c|}
\hline \multirow[t]{2}{*}{ Oksitlenme Tepkimesi } & \multicolumn{3}{|c|}{$\Delta \mathrm{G}^{\mathrm{o}}(\mathrm{kJ})$} \\
\hline & $800^{\circ} \mathrm{C}$ & $1000^{\circ} \mathrm{C}$ & $1200^{\circ} \mathrm{C}$ \\
\hline$Z r B_{2}(k)+\frac{5}{2} O_{2}(g) \Rightarrow Z_{r} O_{2}(k)+B_{2} O_{3}(s)$ & $-1596,5$ & $-1522,4$ & $-1448,3$ \\
\hline
\end{tabular}


numunelerinin ağırlıklarında net artışlar olduğu görülmektedir. Katı $\mathrm{ZrO}_{2}$ tabakalarının yanı sıra sıvı haldeki bor oksidin de oluştuğu düşünülen bu numunelerde net ağırlık artışlarının gözlenmesi, oksit tabaklarının miktarının $1200^{\circ} \mathrm{C}^{\prime}$ de bile buharlaşan bor oksit miktarından daha yüksek olduğuna işaret etmektedir. Grafiklerde ayrıca, $\quad 1000^{\circ} \mathrm{C}^{\prime}$ den itibaren $\mathrm{ZrB}_{2}$ numunelerinin ağırlık artış hızlarının zamanla azaldığı da görülmektedir.

Şekil 5'teki grafiklerde bileşiklerin ağırlık değişimlerinin ortam sıcaklığının artmasıyla arttığı görülmektedir. Buradan, oksitlenme tepkimelerinin Arrhenius tipinde olduğu yani oksitlenme hızının ısı enerjisiyle artan mekanizmalar tarafından kontrol edildiği söylenebilir. Korozyon ürünlerinin bileşiklerdeki elementler ile ortamdaki oksijenin bir araya gelmesiyle oluştuğu düşünülürse, atomik, iyonik veya moleküler yapıdaki kimyasal parçacıkların yayınmalarının (difüzyon), bileşiklerin oksitlenme davranışını kontrol eden önemli bir mekanizma olduğu ortaya çıkmaktadır.

Birçok metal ve bileşiklerin yüksek sıcaklıktaki oksitlenme tepkimeleri kinetik açıdan aşağıdaki matematiksel bağıntıyla (1) açıklanabilir:

$\mathrm{Xn}=\mathrm{k} \cdot \mathrm{t}$

Burada "X", oksitlenen numunenin birim yüzey alanına düşen ağırlık değişimini $(\Delta \mathrm{m} / \mathrm{A})$, " $\mathrm{t}$ ", deney süresini gösterirken "k" da (X) ile (t) arasındaki kinetik ilişkiyi, başka bir değişle, "tepkime hızını" belirtir. Eșitlikteki "n" ise tepkimenin "mekanizması" ile ilgili bir katsayıdır. $\mathrm{Bu}$ katsayı tepkimenin kinetik "derecesi" olarak da düşünülebilir. Katsayının $1,2,3, \ldots$ gibi değerler alması, $(\Delta \mathrm{m} / \mathrm{A})$ ile $(\mathrm{t})$ arasındaki ilişkinin sırasıyla, doğrusal, parabolik ve kübik denklemlerle ifade edilebileceğini gösterir [18].

Buhar basınçları düşük ve kalınlığı zamanla artan katı oksit tabakalarının korozyon ürünleri olarak malzeme yüzeyinde oluştuğu tepkimelerdeki ağırlık artışlarının "parabolik" nitelikte olduğu birçok yüksek sıcaklık oksitlenme çalıșmalarında görülmüștür [18]. $\mathrm{Bu}$ tür tepkimelerin hızlarının, korozyon ürünlerindeki elementlerin yayınma hızlarına bağlı olduğu da belirlenmiştir. Bu çalışmada oksitlenme sırasında zamanla kalınlığı artan katı $\mathrm{ZrO}_{2}$ tabakalarının oluştuğu bileşiğin kinetik davranışlarını inceleyebilmek amacıyla yukarıda Şekil 5'te kullanılan veriler Şekil 6'da $(n=2)$ olacak şekilde, tekrar düzenlenmiştir.

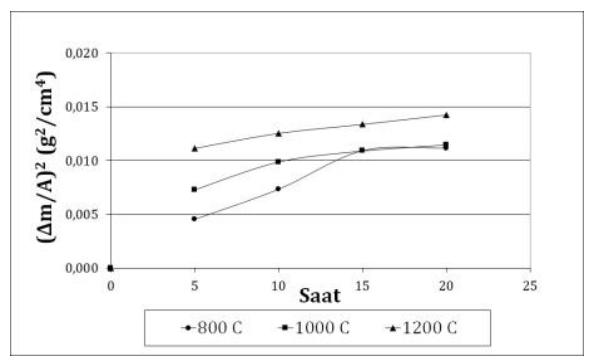

Şekil 6. $\mathrm{ZrB}_{2}$ numunelerinin özgül ağırlık değişimlerinin kareleri $\left[(\Delta \mathrm{m} / \mathrm{A})^{2}\right]$ ile deney süresi (t) arasındaki ilişki

Şekil 6'deki grafiklerde numunelerin özgül ağırlık değişimlerinin karelerinin $\left[(\Delta \mathrm{m} / \mathrm{A})^{2}\right]$ deney süresiyle $(\mathrm{t})$ değişimi gösterildiği için "parabolik" nitelikteki ağırlık artışlarının bu grafiklerde doğrusal olarak görülmesi beklenir. $\mathrm{ZrB}_{2}$ peletler için benzer bir davranışın yaklaşık 15 saat sürdüğü, daha uzun sürelerde ise parabolik davranıştan sapma olduğu görülmektedir.

1000 ve $1200^{\circ} \mathrm{C}^{\prime}$ de alınan deneysel veriler ise, sıcaklık artışıyla korozyon ürünlerinin miktarlarında da artışlar meydana geldiğini göstermektedir. Grafiklerdeki eğrilerden, bileşiklerin bu yüksek sicaklıklardaki kinetik 
davranışlarının parabolik nitelikte olduğunu söylemek zordur. Çünkü numunelerin ağırlık artış hızları bu sıcaklıklarda zamanla azalmıștır. Gözlenen bu tür davranışlara, sıcaklıkla artan buhar basincl nedeniyle bor oksitin numunelerden uzaklaşmasının neden olduğu söylenebilir. Benzer kinetik ve mekanistik davranıșlar $\mathrm{ZrB}_{2}$ için başka çalışmalarda da gözlenmiştir [17].

Yakın zamanda literatüre eklenen bazı çalışmalarda "yüksek sıcaklık seramikleri" olarak adlandırlan $\mathrm{TiB}_{2}$, $\mathrm{ZrB}_{2}$ ve $\mathrm{HfB}_{2}$ bileșiklerinin oksitlenme davranışları için mekanistik ve kinetik modellemeler yapılmıștır. Bunlardan Parthasarathy ve grubunun yaptığ çalışmada, literatürdeki deneysel verilere dayanılarak, bu bileşiklerin oksitlenmeleri sonucunda oluşacak korozyon ürünleri ile içyapılarının, deney sıcaklığına bağlı olarak, Şekil 7'de gösterildiği gibi olacağı ileri sürülmüştür [4].

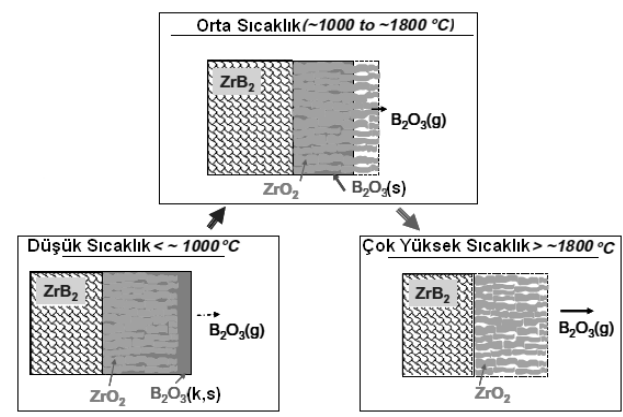

Şekil 7. $\mathrm{ZrB}_{2}$ bileşiğinin $1000-1800^{\circ} \mathrm{C}$ sıcaklıklarda hava ortamında oksitlenmesi için önerilen mekanistik modelin şematik gösterimi (k,s,g kısaltmaları, sırasıyla katı, sıvı ve gaz fazlarını ifade etmektedir) [4].

$\mathrm{Bu}$ modele göre, $\mathrm{ZrB}_{2}$ numunesinin oksitlenmesiyle Tablo 1'de de belirtilen katı $\mathrm{ZrO}_{2}$ ile sıvı bor oksit fazları oluşmaktadır. Ayrıca, oksit tabakaları "kolon" şeklinde büyüyen tanelere sahiptir ve taneler arasinda kalan gözeneklerin alt kısımlarında da sıvı bor oksit bulunmaktadır. Dolayısıyla, $1000^{\circ} \mathrm{C} \quad$ altındaki sicaklıklarda gözeneklerin tamamen sıvı bor oksit ile dolu olacağı, $\quad 1800^{\circ} \mathrm{C}^{\prime}$ den yüksek sicaklıklarda ise bor oksidin buharlaşarak numuneden ayrilması nedeniyle, bu gözeneklerin boşalacağı öngörülmüștür. Detaylı olarak yalnız orta sıcaklık bölgesi için incelenen bu modelde, borür bileşiklerinin oksitlenme hızının, havadaki oksijenin içyapıdaki gözenekler ile sıvı bor oksit içindeki yayınma hızına bağlı olduğu öne sürülmüştür. Şekil 7'de belirtilen çizimler gözeneksiz numune için çizilmiştir. Bu çalışmada parçalar gözenekli olduğu için, verilen şekil gerçekte peletin içindeki ve yüzeye yakın olan her bir partikülün yüzeyindeki durumu göstermektedir. Bununla beraber çalışmada yapılan oksidasyon deneylerinden elde edilen veriler bu modeli destekler niteliktedir.

\section{Sonuç}

Bu çalışmada, soğuk presleme metodu ile şekillendirilmiş gözenekli $\mathrm{ZrB}_{2}$ peletlerinin farklı sıcaklıklarda ve farklı zamanlardaki döngüsel oksidasyon çalışmaları incelenmiştir. $\mathrm{ZrO}_{2}, \mathrm{ZrB}_{2}, \mathrm{~B}_{7} 0$ ve $\mathrm{B}_{2} \mathrm{O}_{3}$ başlica korozyon ürünleri olduğu görülmüștür. Döngüsel oksidasyon davranışının sıcaklığa ve zamana bağlı olduğu gözlemlenmiştir. $800^{\circ} \mathrm{C}$ 'de numuneler parabolik oksidasyon davranışı gösterirken, $1000^{\circ} \mathrm{C}$ ve $1200^{\circ} \mathrm{C}$ sicaklıklarda, $\mathrm{B}_{2} \mathrm{O}_{3}$ fazının buharlaşmasının oksidasyon davranışları üzerinde önemli etkileri olmuştur.

\section{Teşekkür}

$\mathrm{Bu}$ çalışma, Türkiye Bilimsel ve Teknolojik Araştırma Kurumu (TÜBITAK) tarafından desteklenen 105M362 numaralı proje kapsamında gerçekleştirilmiştir. Araştırmacılar desteklerinden dolayı TÜBİTAK'a teşekkür ederler. 


\section{Kaynakça}

[1] Rezaie A, Fahrenholtz WG, Hilmas GE. 2007. Evolution of structure during the oxidation of zirconium diboride-silicon carbide in air up to $1500^{\circ} \mathrm{C}$, Journal of the European Ceramic Society, Cilt. 27, s.24952501. DOI: 10.1016/j.jeurceramsoc.2006.10.0 12

[2] Seong YH, Kim DK. 2014. Oxidation behavior of $\mathrm{ZrB2}-\mathrm{xSiC}$ composites at $1500^{\circ} \mathrm{C}$ under different oxygen partial pressures, Ceramics International, Cilt. 40, s.1530315311. DOI: 10.1016/j.ceramint.2014.07.036

[3] Opeka MM, Talmy IG. Zaykoski J.A. 2004. Oxidation-based materials selection for $2000^{\circ} \mathrm{C}+$ hypersonic aerosurfaces: theoretical considerations and historical experience, Journal of Material Science, Cilt. 39, s.5887-5904. DOI: 10.1023/B:JMSC.0000041686.217 88.77

[4] Parthasarathy TA, Rapp RA, Opeka M, Kerans, R.J. 2007. A Model for the Oxidation of ZrB2, HfB2 and TiB2, Acta Materialia, Cilt. 5, s.5799-6010. DOI: 10.1016/j.actamat.2007.07.027

[5] Han J, Hu P, Zhang X, Meng S, Han W. 2008. Oxidation-resistant ZrB2$\mathrm{SiC}$ composites at $2200^{\circ} \mathrm{C}$, Composites Science and Technology, Cilt. 68, s.799-806. DOI:

10.1016/j.compscitech.2007.08.01 7

[6] Fahrenholtz WG. The ZrB2 Volatility Diagram, Journal of American Ceramic Society, Cilt. 88, No. 12, 2005, s.3509-3512. DOI: $10.1111 /$ j.15512916.2005.00599.x

[7] F. Monteverde, A. Bellosi, S. Guicciardi. 2002. Processing and properties of zirconium diboridebased composites", Journal of the
European Ceramic Society Cilt. 22, s.279-288. DOI: 10.1016/S09552219(01)00284-9

[8] Wang Z, Niu Y, Hu C, Li H, Zen Y, Zheng X, Ren, Sun J. 2015. High temperature oxidation resistance of metal silicide incorporated ZrB2 composite coatings prepared by vacuum plasma spray, Ceramics International, Cilt. 41, s.1486814875.

DOI: 10.1016/j.ceramint.2015.08.015.

[9] Guo WM, Zhang GJ. 2010. Oxidation resistance and strength retention of $\mathrm{ZrB2}-\mathrm{SiC}$ ceramics, Journal of the European Ceramic Society, Cilt. 30, s.2387-2395. DOI: 10.1016/j.jeurceramsoc.2010.01.0 28

[10] Sarin P, Driemeyer PE, Haggerty RP, Kim DK, Bell JL, Apostolov ZD, Kriven WM. 2010. In situ studies of oxidation of $\mathrm{ZrB} 2$ and $\mathrm{ZrB} 2-\mathrm{SiC}$ composites at high temperatures, Journal of the European Ceramic Society, Cilt. 30, s.2375-2386. DOI: 10.1016/j.jeurceramsoc.2010.03.0 09

[11] Talmy IG, Zaykoski JA, Opeka MM. 2008. High-Temperature Chemistry and Oxidation of ZrB2 Ceramics Containing SiC, Si3N4, Ta5Si3, and TaSi2, Journal of American Ceramic Society, Cilt. 91, No. 7, s.2250-2257. DOI: $10.1111 / \mathrm{j} .1551-$ 2916.2008.02420.x

[12] Dehdashti MK, Fahrenholtz WG, Hilmas GE. 2014. Effects of temperature and the incorporation of $\mathrm{W}$ on the oxidation of $\mathrm{ZrB} 2$ ceramics, Corrosion Science, Cilt. 80, s.221-228. DOI: 10.1016/j.corsci.2013.11.030

[13] Dehdashti MK, Fahrenholtz WG, Hilmas GE. 2015. Effects of transition metals on the oxidation behavior of $\mathrm{ZrB} 2$ ceramics, Corrosion Science, Cilt. 91, s.224- 
E. Dokumacı vd. / Gözenekli ZrB 2 Peletlerin Farklı Sıcaklıklardaki Oksidasyon Davranışları

231.

10.1016/j.corsci.2014.11.019

[14] Dong ZH, Peng X, Wang FH. 2015. Oxidation of a ZrB2 coating fabricated onTa-W alloy by electrophoretic deposition and laser melting, Materials Letters, Cilt. 148, s.76-78. DOI: 10.1016/j.matlet.2015.02.075

[15] Türkdoğan E.T. 1980. Physical Chemistry of High Temperature Technology, Academic Press, 462s.

[16] Lee DB, Lee YC, Kim DJ. 2001. The Oxidation of TiB2 Ceramics
Containing $\mathrm{Cr}$ and $\mathrm{Fe}$, Oxidation of Metals, Cilt. 56, No. 1, s.177-189. DOI: 10.1023/A:1010369526960

[17] Irving RJ, Worsley IG. 1968. The Oxidation of Titanium Diboride and Zirconium Diboride at High Temperatures, Journal of Less Common Metals, Cilt. 16, s.103112. DOI: $10.1016 / 0022-$ 5088(68)90067-2

[18] Kofstad P. 1988. High Temperature Corrosion, Elsevier Applied Science Publishers, England, 558s. 